\title{
Наука, создающая и внедряющая высокие технологии
}

\author{
Рассказывает Леонид Александрович Карпюк, \\ генеральный директор АО «ВНИИНМ» имени академика А. А. Бочвара
}

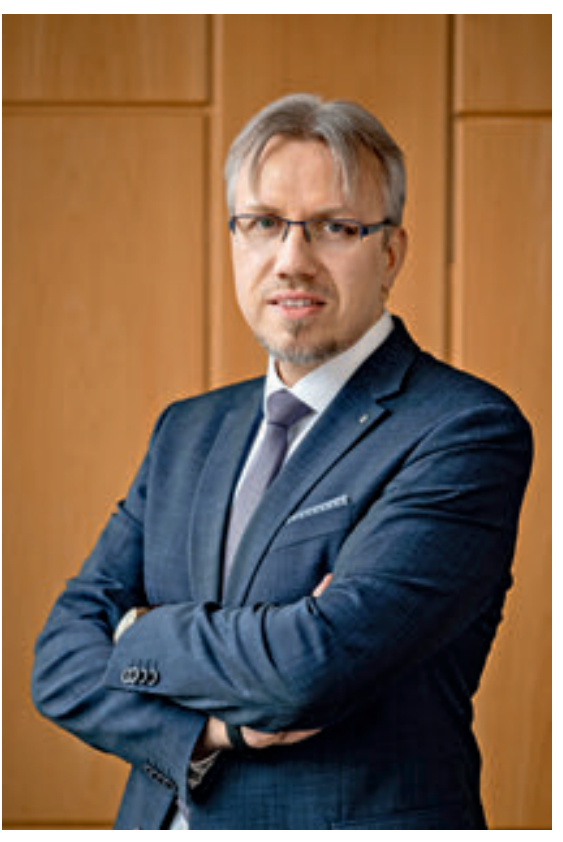

В 2020 году Высокотехнологическому научно-исследовательскому институту неорганических материалов имени академика А. А. Бочвара (АО «ВНИИНМ», входит в структуру топливного дивизиона «Росатома») исполняется 75 лет. При непосредственном участии сотрудников института созданы ядерный щит государства, атомный флот, современные АЭС и космические аппараты - это то, что сегодня является предметом гордости нашей страны.

Институт внес неоценимый вклад в развитие отечественного атомного проекта: это и первые в СССР экземпляры металлического плутония, топливо для тепловых и быстрых реакторов, полониевые источники тепла для аппаратуры «Лунохода», топливо для ледоколов и многое другое. Признанием заслуг и роли ВНИИНМ в развитии науки и техники стало присвоение ему статуса Государственного научного центра РФ.

О вкладе института в развитие современных технологий, основных направлениях работы, интересных и перспективных проектах, кадровой политике, программе технического перевооружения нам рассказал генеральный директор АО «ВНИИНМ» Леонид Александрович Карпюк.

\begin{abstract}
Уважаемый Леонид Александрович, расскажите, пожалуйста, об основных направлениях работы и проектах, которые реализуются в институте.
\end{abstract}

Сегодня институт - один из ведущих научноисследовательских центров и головная организация Госкорпорации "Росатом" по проблемам материаловедения и технологий ядерного топливного цикла. Важнейшую роль институт играет в научнотехническом сопровождении работы Топливной компании "ТВэЛ», причем как в области разработок ядерного топлива, так и технологической поддержки новых, высокотехнологичных направлений.

AО «ВНИИНМ» принимает участие в важнейших отраслевых проектах, лежащих в основе стратегии Госкорпорации "Росатом". Основные относятся к разработке новых видов ядерного топлива. Это создание конструкционных материалов и смешанного нитридного уран-плутониевого топлива для реакторов на быстрых нейтронах, разработка топлива для новейших атомных станций малой мощности, участие в проектировании топливной композиции для инновационного жидкосолевого реактора. И, конечно же, совершенствование топлива для тепловых реакторов типа ВВЭР (водо-водяной энергетический реактор). В этом направлении институт является главным идеологом и разработчиком так называемого "толерантного топлива" - топлива устойчивого к авариям. Кроме этого, институт занимается разработкой технологии низкотемпературных и высокотемпературных сверхпроводников и рядом других, не менее важных направлений.

\section{Какие достижения вы считаете самыми важ- ными? Какие наиболее приоритетны?}

В институте действует десять научных направлений, в каждом реализуется по несколько проектов отраслевого значения. При таком объеме решаемых задач выделить самое значимое достижение непросто.

В течение прошлого года институт продолжал исследования в рамках проектных направлений «Прорыв» - топливо для быстрых реакторов 
и "толерантное топливо". Это серьезный вклад наших ученых в повышение уровня безопасности процессов атомной энергетики.

В рамках выполнения функции главного научного метрологического центра Госкорпорации "Росатом" специалисты ВНИИНМ провели серию межлабораторных сличительных испытаний, которые позволяют устанавливать и поддерживать единый высокий стандарт работ в отрасли.

По итогам выполнения международного контракта с Европейским центром ядерных исследований (ЦЕРН) в рамках работ по проекту Кругового Коллайдера Будущего (FCC) разработаны и изготовлены образцы ниобий-оловянных стрендов различной конструкции и легированием. Наши ученые достигли требуемой плотности критического тока стренда в магнитном поле. В этом направлении ВНИиНМ также обладает уникальными компетенциями и занимает ведущие позиции в мире среди разработчиков технологий сверхпроводимости. В этом году мы начали наращивать потенциал в области высокотемпературной сверхпроводимости. Изготовлена опытная партия керамиче ских мишеней различных химических составов для напыления слоя ВТСП (высокотемпературного сверхпроводника). Начаты работы по разработке принципиально новой, более производительной и экономически эффективной, технологии изготовления ВТСП-2.

Еще одно новое и чрезвычайно наукоемкое направление, которое появилось у нас в этом году проект “Жидкосолевой реактор". В рамках него проведен анализ технических предложений по технологиям переработки ОЯТ ЖСР, включая предварительный анализ технологических схем подготовки и переработки топливных композиций ЖСР на основе несущих солей - фторидов лития, натрия, калия и фторидов лития и бериллия. Проведена оценка характеристик схем, таких как времена рециклирования актинидов, потребности в исходных материалах и объемы радиоактивных отходов. Этот проект должен существенно продвинуть тему окончательного дожигания опасных отходов.

Также необходимо отметить внедрение технологии изготовления источников бета-излучения и бетавольтаических источников энергии на основе трития. Работа выполнена по заказу "Роскосмоса" и демонстрирует спектр научных компетенций ВНИИНМ на сегодня.

\section{I Каковы источники финансирования проектов?}

Наука, создающая и внедряющая высокие технологии, работает на обеспечение независимости государства, служит на благо своему отечеству. Как и современная, сильная армия. Ключевыми нашими заказчиками является государство, Госкорпорация "Росатом" и предприятия отрасли.

\section{I Какими ноу-хау обладает институт?}

Для института важно, чтобы разработки наших ученых коммерциализировались и использовались при выполнении новых и перспективных научноисследовательских работ не только в контуре Госкорпорации "Росатом", но и во всем мире. Балансовая стоимость портфеля интеллектуальной собственности института сегодня составляет более 80 млн руб. На данный момент в АО "ВНИИНМ" имеется 664 объекта интеллектуальной собственности, тематика которых отражает все направления деятельности института: топливные и конструкционные материалы, сверхпроводниковые материалы, радиохимия и др.

\section{I Какой инфраструктурой располагает институт?}

Сегодня институт обладает всей необходимой инфраструктурой для проведения исследований в своей области задач. Но нужно учитывать, что технологии не стоят на месте. В зоне нашей ответственности - организация современных рабочих мест, отвечающих мировым требованиям. В первую очередь это касается технического оснащения всех направлений работ института. При этом необходимо создать все условия для того, чтобы наши сотрудники эффективно и комфортно работали на своем месте. Мы уделяем этому достаточно много внимания.

В начале 2019 года в институте сформирована программа технического перевооружения. Программа разработана на пять лет - до 2024 года включительно. Выполнение программы включает приобретение самого современного оборудования, необходимого для проведения исследований на мировом уровне. Для нашего института это принципиально важная задача. Наш общий успех зависит от уровня компетенций научных сотрудников, который должен быть выше, чем в других институтах, равно как и от качества и сложности того оборудования, на котором проводятся исследования. 


\section{История}

Акционерное общество «Высокотехнологический научноисследовательский институт неорганических материалов имени академика А. А. Бочвара» (АО «ВНИИНМ») - один из ведущих научно-исследовательских материаловедческих центров Госкорпорации "Росатом", входит в структуру управления Топливной компанией Росатома «ТВЭЛ».

АО «ВНИИНМ» является Государственным научным центром (ГНЦ), который представляет собой многопрофильный специализированный институт, способный решать задачи, начиная с фундаментальных и прикладных исследований до создания наукоемких изделий и технологических процессов их освоения на предприятиях атомной отрасли России, в других отрасляхпромышленности, а также по контрактам для зарубежных партнеров.

Институт (Инспецмет), или легендарная "девятка" (НИИ-9), был создан в 1944-1945-х годах прошлого столетия для решения материаловедческих и технологических проблем разработки ядерного оружия с целью ликвидации монополии США в этой области.

Более 30 лет его возглавлял академик Андрей Анатольевич Бочвар - основатель отечественной школы ядерного материаловедения, имя которого с гордостью носит институт сегодня.

На протяжении почти 70-летней истории тематика института постепенно трансформировалась в направлении мирного использования ядерной энергии, создания новых тепловыделяющих элементов, функциональных и конструкционных материалов, технологий производства изделий из них, работающих в различных областях и сферах деятельности человека.

Сегодня институт является комплексным предприятием по разработке технологий замкнутого ядерного топливного цикла для атомной энергетики, созданию конструкционных, функциональных, сверхпроводящих материалов,

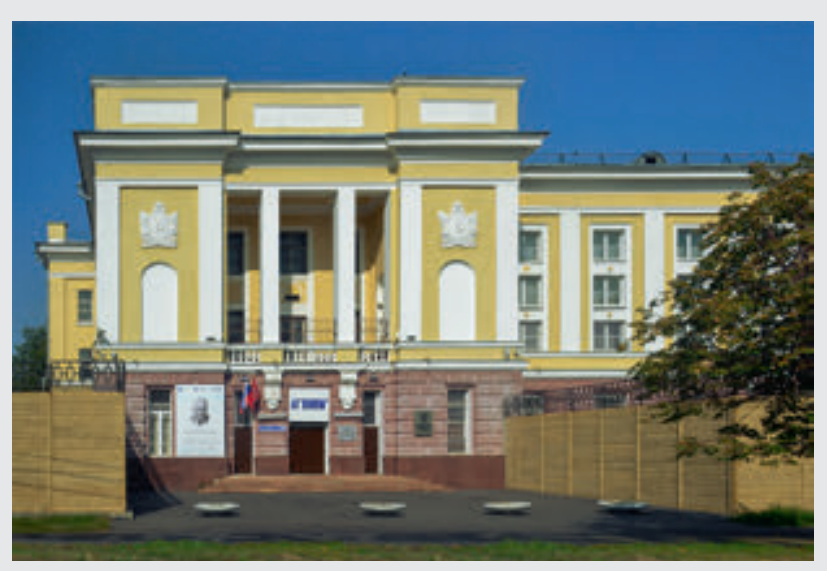

а также технологий и оборудования специальной неядерной и изотопной продукции, технологий обращения с отработанным ядерным топливом (ОЯт), радиоактивными отходами (РАО) и выводу из эксплуатации.

Исследовательская база института расположена на территории 19,6 га в районе Щукино, недалеко от Москвы-реки, и состоит из нескольких современных материаловедческотехнологических и радиохимических комплексов и стендов.

В АО «ВНИИНМ» созданы и успешно функционируют опытно-промышленные участки по производству низкотемпературных сверхпроводников, изделий из гафния, бериллия, магнитных, фильтровальных материалов, нанесению уникальных покрытий, по исследованию уран-плутониевого и других видов топлива.

В разное время в институте работали выдающиеся отечественные ученые металловеды и металлурги, радиохимики и физико-химики - академики А. А. Бочвар, А. Н. Вольский, А. С. Никифоров, Ф. Г. Решетников, членыкорреспонденты А. С. Займовский, С.Т. Конобеевский, А. Г. Самойлов, М. И. Солонин, В. В.Фомин, пионеры атомной отрасли и института - доктора наук В. Б. Шевченко, 3. В. Ершова и многие др.

\section{| Расскажите о вашей кадровой политике.}

Откровенно говоря, с кадрами в науке сейчас не просто. На рынке труда существуют более высокооплачиваемые вакансии, которые требуют меньших умственных способностей и затрат сил, чем научная деятельность.

В целом во ВНИИНМ разработан план мероприятий, направленный на привлечение молодых специалистов и ученых. Мы провели анализ деятельности научных подразделений с целью повышения роли молодых сотрудников в работе института. Для поддержки молодых ученых в институте запущена программа наставничества, целью которой является подготовка преемников на ключевые должности, а также информирование молодежи о перспективах и возможностях научного роста. Серьезное внимание уделяется и социальной политике. Например, с этого года во ВНИИНМ заработала жилищная программа. Она направлена на поддержание как ключевых специалистов - кандидатов и докторов наук, так и на молодежь.

Стоит отметить, что во ВНИИНМ функционирует филиал 9-й кафедры МИФИ, где проходят обучение и практику студенты выпускных курсов этой кафедры. 
В 2020 году мы значительно (почти в два раза) увеличили затраты на обучение. Ключевыми направлениями являются повышение квалификации и дополнительное обучение для научных сотрудников, а также английский язык, знание которого необходимо для квалифицированного ученого мирового уровня.

\section{Как реализуется связь института с промыш- ленностью?}

Эта связь прямая - все наши разработки внедряются в промышленность и реализуются на предприятиях Госкорпорации "Росатом". Это касается циркониевой продукции, топлива для различных реакторных установок, сверхпроводников и многих других продуктов и технологических решений. По этой схеме ВНИИНМ успешно работает уже 75 лет.

Какие меры, с вашей точки зрения, необходимы для поддержки российской фундаментальной и прикладной науки?

Для эффективного развития науки, и фундаментальной, и прикладной, нужно, чтобы три фактора сработали одновременно. Это ресурсы в виде профессиональных ученых, современная технологическая база и перспективные масштабные задачи. В нашем высокотехнологическом веке недостатка задач нет. Появляется множество новых научных направлений, причем не обособленных друг от друга, а наоборот, формирующихся на стыке различных областей. Полет фантазии неограничен практически ничем. Важно, только чтобы научные организации умели смотреть шире области своих профессиональных интересов.

Что же касается современного оборудования, то тут могут возникать сложности и не только финансового характера. Геополитическая обстановка накладывает свои ограничения: не всегда, даже имея финансовый ресурс, удается приобрести самое современное оборудование зарубежного производства. Как

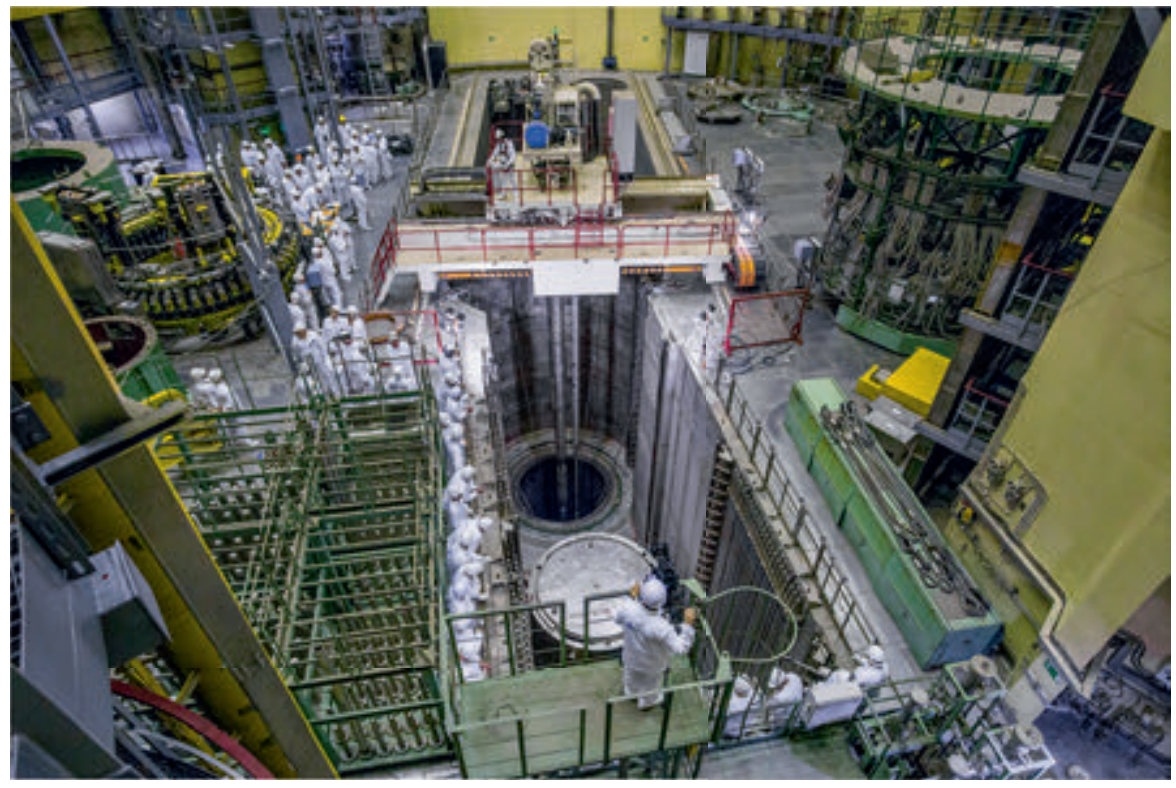

следствие, одной из важнейших задач является разработка отечественных аналогов.

Третий фактор самый важный это люди. Наша страна всегда была богата талантливыми учеными. Это справедливо и сегодня. Выпускников наших вузов ценят во всем мире. Именно поэтому многие наши соотечественники уезжают за границу и предпочитают работать там. Это заметная потеря для нашего государства. Принципиально важной задачей является обеспечение достойного уровня жизни для работников науки в нашей стране. И, конечно, нужно восстановить высокий авторитет звания ученого. Над этим мы тоже работаем.

\section{Насколько эффективно сотрудничество с вузами?}

Мы очень плотно работаем с ведущими российскими университетами и вузами - МГУ им. М. В. Ломоносова, МИФИ, РХТУ, МИСИС и пр. Студенты проходят у нас практику, многие после защиты диплома устраиваются к нам на работу. Кроме этого, мы привлекаем учебные заведения к участию в наших проектах в качестве соисполнителей.

\section{Спасибо за интересный рассказ.}

С Л.А.Карпюком беседовала О.А. Лаврентьева 


\section{УЧАСТИЕ ИНСТИТУТА В ВАЖНЕЙШИХ}
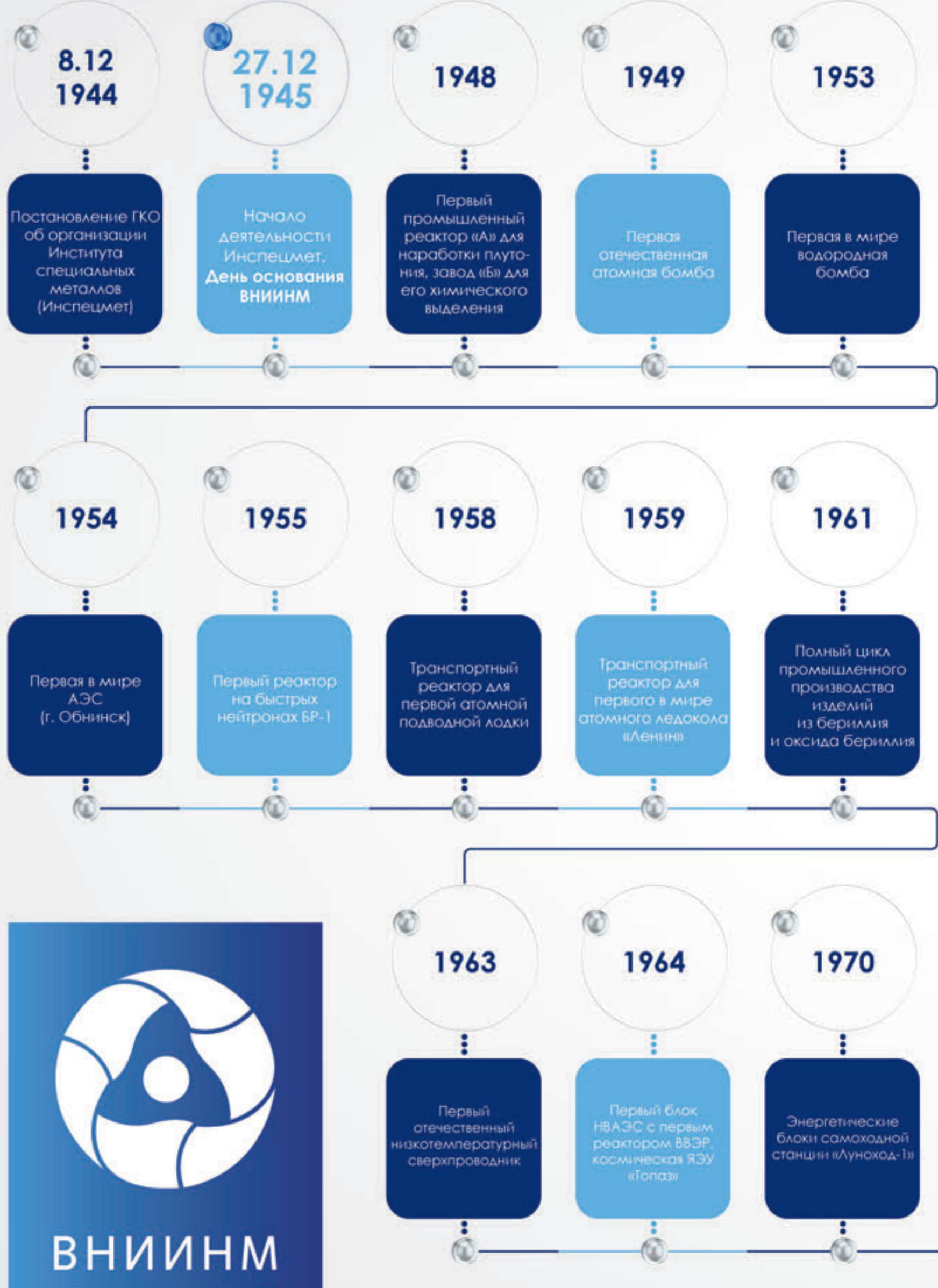

(B)

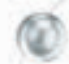

омышленного

ромзвОАСТВ

ИзАеАии

43 беримаия

сйа беримаи 


\section{ГОСУААРСТВЕННЫХ ПРОЕКТАХ}

(2)

2015
(2)

2016

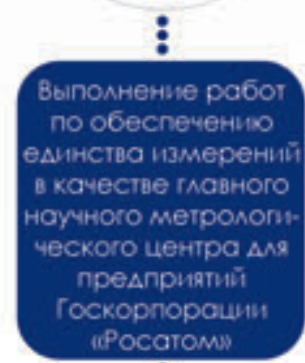

8

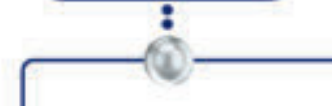

(2)

2018

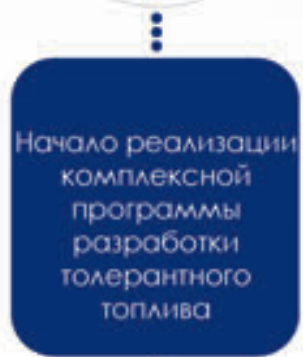

:
(2) 2019

2020

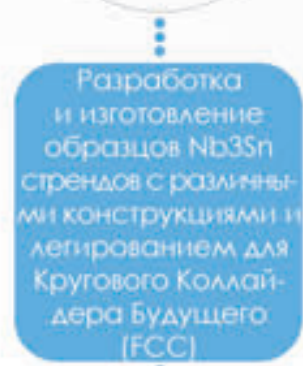

(1)

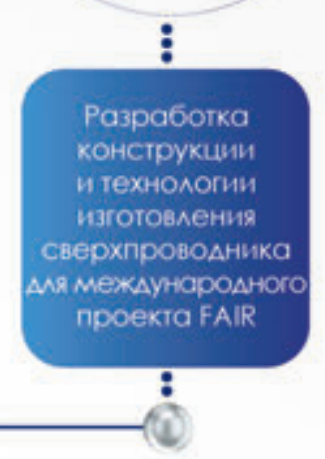

(2)

2014
2010

:

Руководство

СозАанием отече-

ственного пронз.

BOАCтва специаль-

ных изАемий из

беримияя на ФГУП

"Базаньт) (Capatoв)

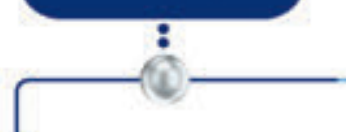

(2)

1978

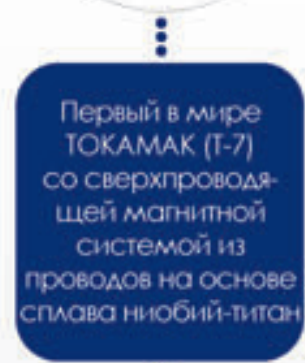
:
(8)

2011

2012

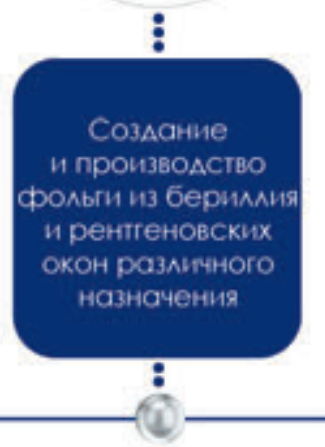

2013
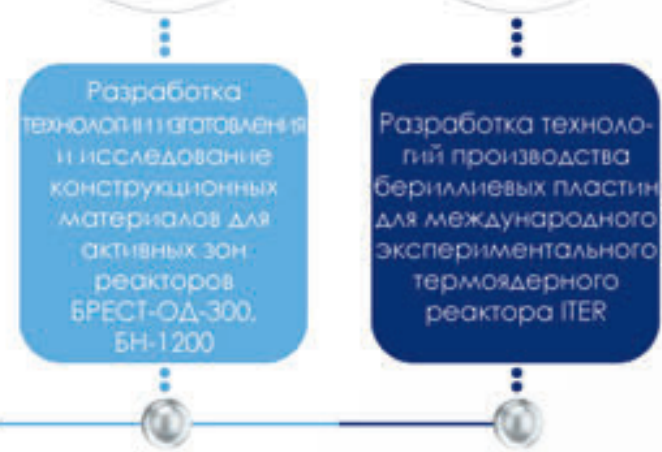

(2)

2001

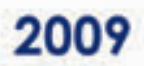

